\title{
Comparison of treatment outcome following rubber band ligation vs injection scleratherapy for treatment of hemorrhoids: a prospective observational study
}

\author{
Chandrabose K. ${ }^{1}$, Subbiah V. ${ }^{2}$ \\ ${ }^{1}$ Dr. Karpagavel Chandrabose, ${ }^{2}$ Dr. Venkatesh Subbiah, both authors are affiliated with Department of General Surgery, \\ Velammal Medical College, Madurai, Tamil Nadu, India.
}

Corresponding Author: Dr. Venkatesh Subbiah, Velammal Medical College, Madurai, Tamil Nadu, India. Email: venkateshpims@gmail.com

\begin{abstract}
Background: Most common anorectal diseases seen in the community is hemorrhoids. The treatment aspect of each stage of hemorrhoids varies. Conservative treatment for first and second stages is preferred. Failure of conservative treatment and advanced diseases hasother options like sclerotherapy, ban ligation, cryosurgery and stapling. The objective of the present study is to compare treatment outcome of rubber band ligation and sclerotherapy in stage 2 hemorrhoid cases. Methods: Prospective observational study including uncomplicated stage 2 hemorrhoids cases was conducted in department of general surgery, Velammal Medical College. Madurai. The study population was divided into two groups by random allocation treatment procedure of rubber band ligation or sclerotherapy was allotted. The study was conducted during March 2018 to December 2018. Results: Total of 116 patients were included for analysis. The mean of group I was 53.2 \pm 4.63 yrs and in group II was $52.7 \pm 5.37$ yrs. The male and female distribution was almost similar in both groups. 41 of the group I patients and 37 of group II patients had stage 2 disease. $29 \%$ in group I and $36 \%$ in group II had stage 3 disease. In group I, $82.75 \%$ participants had complete recovery and $10.35 \%$ participants had partial recovery. In group II, $79.31 \%$ participants had complete recovery and $17.51 \%$ participants had partial recovery. The difference in the proportion of post-operative outcomes between study groups was statistically not significant. Comparison of pre and post-operative SS score between the two study groups was statistically significant. Conclusions: Stage 2 and 3 hemorrhoids warranting OPD based interventional procedures were presented with almost similar set of symptoms. The rubber band ligation and injection sclerotherapy both had similar post treatment outcome. Based on the patient's willingness and surgeons' decision any method can be chosen for the benefit of the patient.
\end{abstract}

Keywords: Hemorrhoids, Rubber band ligation, Sclerotherapy

\section{Introduction}

Hemorrhoids are most common, affecting up to one quarter of all adults according to some estimates. Large number of interventions exists for their management. These range from topical and medical therapies to outpatient treatments and surgical interventions that aim to fix or excise[1]. Hemorrhoids are polysymptomatic, making it difficult to judge on the management course.

Recently introduced novel hemorrhoid management techniques, such as stapled haemorrhoidopexy, Ligature excision and hemorrhoidal artery ligation, aim to reduce harm whilst maintaining or improving on outcome[2].

Manuscript Received: $30^{\text {th }}$ January 2019

Reviewed: $8^{\text {th }}$ February 2019

Author Corrected: $14^{\text {th }}$ February 2019

Accepted for Publication: $19^{\text {th }}$ Februry 2019
"These new techniques are universally more expensive, and available good quality data suggest the additional cost does not necessarily equate to universally better outcomes compared with traditional older interventions, such as rubber band ligation and excision hemorrhoidectomy [3]. Whatever the intervention selected for treatment, it is clear that this should be tailored to the individual based on patient choice, convenience and degree of hemorrhoids.

Hemorrhoids represent pathological changes inthe anal cushions, a normal component of theanal canal involved in aiding evacuation of stooland fine-tuning of anal continence. These pathological changes include rupture of the supporting connective tissue within the cushions, 


\section{Original Research Article}

resulting inenlargement of the vascular plexus[4]. The pathogenesis of hemorrhoids explains the symptoms associated with the condition: bleeding, swelling and prolapse, seepage due to the disruption of thefine tuning of continence and consequent irritation of the perianal skin. More severe symptoms may include thrombosis leading to pain[5].Treatment options for hemorrhoids are varied; however, the evidence base for many of the seoptions has, until recently, been poor.

Despitethe poor scientific substantiation, some of the set treatment options have stood the clinical test of time. However, many new options have been introduced since the turn of the century[6]. There isrecent scientific support for some of these neweroptions that allow an evidence-based update to management [4].

The objective of the present study was to compare treatment outcome among patients undergoing rubber band ligation and sclerotherapy for hemorrhoids.

\section{Methods}

Study settings: The study was conducted in the department of general surgery Velammal Medical College. Madurai. Prospective recruitment of cases was done based on selection criterion. The study was conducted during March 2018 to December 2018. The study was approved by institutional ethical committee of Velammal Medical College, Madurai.

Study Participants: Patients diagnosed with grade 2 and 3 haemorrhoids were recruited after obtaining informed consent.

Sampling Methods: The sampling technique used was consecutive non probability sampling. The patients were divided into two groups based on computer generated list of random numbers. Group I was allocated Rubber band ligation and Group II was allocated Sclerotherapy.

Inclusion Criteria: Male and female patients of more than 20 years and above presenting with bleeding per rectum with or without associated symptoms like mucosal prolapse, discharge, pruritis and pain as well having being diagnosed on history and proctoscopy findings like visible bleeding and engorged anal cushions were included in the study.

Exclusion criteria: Patients having bleeding diathesis, or on anticoagulants, having anal fissure and/or perianal abscess, pregnant ladies or having any other advanced disease were excluded from the study.
Random Allocation: The procedure and its associated complications were explained to each patient in detail. SS score was noted at the time of presentation on the basis of history. Degree of haemorrhoids was ascertained on an proctoscopy in all patients. They were divided into two groups RBL and IST based on computer generated table of random numbers. Rubber band ligation was done in RBL group and IST was done in IST group patient as an OPD procedure.

Rubber band ligation: In RBL group, each patient was briefed about the procedure and placed in knee elbow position. Barron's Gun and Elise's tissue forceps were used to apply the Rubber Band at the base of each haemorrhoid.

Injection sclerotherapy: After anoproctoscopy and proper identification of position and degree of haemorrhoids, haemorrhoidal tissue was grasped with Elise's tissue forceps through Barron's Gun and rubber band was placed at insensitive area above the dentate line. In IST group, each Patient was briefed about the procedure and placed in knee elbow position. No bowl preparation was done.

Five percent phenol in almond Oil was taken in a disposable syringe with 20 -gauge spinal needle and a well lubricated proctoscope was inserted gently into the rectum. Obturator was removed and proctoscope slowly withdrawn till the pedicle of the haemorrhoid to be injected became visible. Needle of the syringe was inserted into the submucosal plane of the pedicle above the dentate line. Suction with the needle was done to rule out any possibility of intravascular injection.

After confirmation of proper placement of needle in submucosal plane, $3-5 \mathrm{ml}$ of the solution was injected into each pile in a single setting. No more than two haemorrhoids were injected at a time. After the withdrawal of the needle, oozing of the solution was stopped by applying local pressure with a gauze pack and forceps for 2-3 minutes which also helped in controlling the bleeding from injection site.

Patients were informed about the heaviness and occasionally desire to defecate after the injection. Post injection patients were advised not to try to defecate for next 24 hours. They were also advised not to strain and to contact the doctor in case of any problem in relation to treatment. Patients in both groups were observed for 30 minutes for immediate complications like pain and bleeding. Repeat anoproctoscopy was done to look for bleeding if necessitated in these patients. 


\section{Original Research Article}

Follow Up: Patients were then followed up on 15th post procedure day and improvement in SS score was noted. Patient's personal data, presenting complaints, findings on general physical and rectal examination, initial SS score, procedure done, any complications, final SS

\section{Results}

A total of 116 patients, with 58 people in Rubber Band Ligation (group I) and 58 patients in IST (group II) were included in the final analysis.

Table-1: Comparison of baseline characteristics of study population.

\begin{tabular}{|c|c|c|c|}
\hline Parameter & $\begin{array}{c}\text { Group I(RBL) } \\
\mathbf{N}=\mathbf{5 8}\end{array}$ & $\begin{array}{c}\text { Group II (IST) } \\
\mathrm{N}=\mathbf{5 8}\end{array}$ & $P$ value \\
\hline Age & $53.2 \pm 4.63$ & $52.7 \pm 5.37$ & 0.592 \\
\hline \multicolumn{4}{|l|}{ Gender } \\
\hline Male & $33(57 \%)$ & $37(63 \%)$ & \multirow{2}{*}{0.447} \\
\hline Female & $25(43 \%)$ & $21(37 \%)$ & \\
\hline BMI & $26.8 \pm 5.78$ & $25.93 \pm 4.93$ & 0.385 \\
\hline Mean duration of illness in days & $37 \pm 8.43$ & $43 \pm 7.78$ & 0.001 \\
\hline \multicolumn{4}{|l|}{ Presenting symptoms } \\
\hline - Bleeding per rectum & $58(100 \%)$ & $58(100 \%)$ & $*$ \\
\hline - Mucosal prolapse & $37(63.79 \%)$ & $33(56.89 \%)$ & 0.447 \\
\hline - Associated pruritus & $10(16 \%)$ & $8(13.79 \%)$ & 0.608 \\
\hline - Associated Pain & $15(25.86 \%)$ & $17(29.31 \%)$ & 0.677 \\
\hline - Discharge per rectum & $12(20 \%)$ & $10(17.24 \%)$ & 0.635 \\
\hline \multicolumn{4}{|l|}{ Grade of haemorrhoids } \\
\hline I & $0(0 \%)$ & $0(0 \%)$ & \multirow{3}{*}{ * } \\
\hline II & $41(70.69 \%)$ & $37(63.79 \%)$ & \\
\hline III & $17(29.31 \%)$ & $21(36.21 \%)$ & \\
\hline
\end{tabular}

*No statistical test was applied- due to 0 subjects in the cells

The mean age was $53.2 \pm 4.63$ years in people with group 1 (RBL) and it was $52.7 \pm 5.37$ years in people with group II (IST) group. The difference between two groups was statistically not significant (P value 0.592). In group I (RBL), 33(57\%) participants were male and remaining 25 (43\%) participants were female. In group II (IST), 37 (63\%) participants were male and remaining 21 (37\%) participants were female.

The difference in the proportion of gender between study groups was statistically not significant (P value 0.447$)$. In group I (RBL), for all 58 (100\%) participants had bleeding per rectum. In group II (IST), for all 58 (100\%) participants had bleeding per rectum. The difference in the proportion of mucosal prolapse between study group was statistically not significant (P value 0.447).

The difference in the proportion of associated pruritus between study group was statistically not significant ( $\mathrm{P}$ value 0.608). The difference in the proportion of associated Pain between study group was statistically not significant ( $\mathrm{P}$ value 0.677). The difference in the proportion of discharge per rectum between study group was statistically not significant (P value 0.635). The mean BMI was $26.8 \pm 5.78$ in people with group 1 (RBL) and it was $25.93 \pm 4.93$ in people with group II (IST) group. The difference between two groups was statistically not significant (P value 0.385 ).

The mean duration of illness was $37 \pm 8.43$ days in people with group 1 (RBL) and it was43 \pm 7.78 days in people with group II (IST) group. The difference between two groups was statistically significant (P value 0.001). In group I (RBL), $21(70 \%)$ participants were grad II and $9(30 \%)$ participants were grade III. In group II (RBL), 19(63.33\%) participants were grad II and 11 (36.67\%) participants were grade III. 
Original Research Article

Table-2: Comparison of post-operative outcomes between the study groups

\begin{tabular}{|c|c|c|c|}
\hline Parameter & Group I(RBL)N=58 & Group II (IST)N=58 & P value \\
\cline { 1 - 3 } Complete recovery & $48(82.75 \%)$ & $46(79.31 \%)$ & \multirow{2}{*}{0.425} \\
\cline { 1 - 3 } Partial recovery & $6(10.35 \%)$ & $10(17.51 \%)$ & \\
\hline No recovery & $4(6.89 \%)$ & $2(3.44 \%)$ & \\
\hline
\end{tabular}

In group I (RBL), $48(82.75 \%)$ participants had complete recovery and 6 (10.35\%) participants had partial recovery. In group II (IST), 46 (79.31\%) participants had complete recovery and 10 (17.51\%) participants had partial recovery. The difference in the proportion of post-operative outcomes between study group was statistically not significant (P value 0.425). (Table 2)

Table-3: Comparison of pre and post-operative SS score between the two study groups.

\begin{tabular}{|c|c|c|c|}
\hline Parameter & Group I(RBL)N=58 & Group II (IST)N=58 & P value \\
\hline Pre-operative SS score & $4.49 \pm 1.89$ & $1.25 \pm 0.89$ & 0.001 \\
\hline Post-operative SS score & $4.52 \pm 1.63$ & $4.52 \pm 0.78$ & 1.000 \\
\hline
\end{tabular}

The mean pre-operative SS score was $4.49 \pm 1.89$ in people with group1 (RBL) and it was $1.25 \pm 0.89$ in people with group II (IST) group. The difference between two groups was statistically significant (P value 0.001). The mean duration of illness was $4.52 \pm 1.63$ in people with group 1 (RBL) and it was4.52 \pm 0.78 in people with group II (IST) group. The difference between two groups was statistically not significant (P value 1.000). (Table 3)

\section{Discussion}

Hemorrhoids develop from engorgement and prolapse ofthe submucosal anal cushion, which composed of an interlacingarteria-venous hemorrhoidal plexus, supported byconnective tissue and minute muscle fibres[7]. Hemorrhoids occur universally and are found since ancient times. The etiology remains indecisive and mostly patients present after the development of symptoms. The symptoms range from bleeding per rectum to prolapse of the mucosa.

All symptomatic cases need treatment indefinitely. Due to social stigma and hesitancy patient delay seeking medical care and mostly present with grade 2 or 3 hemorrhoids. So, every bleeding per rectum is considered are due to hemorrhoids until proved otherwise. Rubber band ligation is an optimal outpatient procedure for hemorrhoids and rectal mucosal prolapse.

A prospective randomized trial done by Murie et al [8]RBL was equally effective as that of haemorrhoidectomy in treating second grade hemorrhoids. RBL was effective $70 \%$ in treating third grade hemorrhoids. They proved that even the complications after the procedure was minimal and manageable. RBL being an OPD procedure reduced the need for hospital stay and resource wastage. A study done by Ambrose et a showed that infrared photocoagulation also was as good as RBL. However, the group randomized to the photocoagulation arm required furtherout-patient treatment more often than the RBL arm [2]. Poenetal [9] showed in a randomized controlled trial that RBL andinfrared coagulation were equally effective, but pain was significantly more common and more severe in the RBL group. In the present study the male preponderance was observed, similar to Khan et al study[10]. Half of men and women aged above fifty years have the chances of developing hemorrhoids in their life time[2]. In this present study, the mean age of participants was53.2 \pm 4 .63years, 52.7 \pm 5.37 years respectively in groups. This was similar to the findings observed in various studies that hemorrhoids occurred more commonly among people above 50 yrs of age $[11,12]$. Injecting sclerotherapy is indicated in first grade hemorrhoids with bleeding and second grade hemorrhoids.

Sclerotherapy is the gold standard in the first-degree hemorrhoid treatment similar to rubber band ligation, injection sclerotherapy may also be undertaking in the outpatients setting $[4,13]$. Among Treatments that prevents the progression of disease, sclerotherapy has less number of complications and good compliance [5]. Pain is the most common complain after the procedures. The patient often complains of intra anal discomfort. The reported incidence of pain following injection sclerotherapy ranges from $9 \%$ to $70 \%$ and in RBL 5 to $85 \%$ [14]. The other significant side effect reported is rectal bleeding. It is seen in $2-10 \%$ of casesafter sclerotherapy, 1 to $15 \%$ after rubber band ligation[15]. The Chew et al combined injection sclerotherapy with 


\section{Original Research Article}

RBL achieved 90 percent of success. The complication rate was of 3.1 percent with an overall recurrence rate of 16 percent. Only 7.7 percent of thesepatients required hemorrhoidectomy [16]. Proper technique and making office treatment for first to thirdgrade hemorrhoids tolerable and satisfying[17]. Kaman L et al reported a patient who underwent submucosal injection sclerotherapy for hemorrhoids andpresented with necrotizing fasciitis of the anorectum, perianal region and scrotum. Post-operatively, the patient developed septicemia and renal failure requiring an extended hospital stay[18].

In this present study after treatment with injection sclerotherapy, $79.31 \%$ had complete recovery. In a study Bhuiya et al using 5\% phenol in olive oil as sclerosant satisfactory results were seen in $60.41 \%$ patients after the first dose, $15.78 \%$ patients after the second dose and $3.12 \%$ after the third dose injection sclerosant[19]. In Rubber band ligation group 83.3\% had complete recovery. Proving that both RBL and injection sclerotherapy can be an effective treatment for grade 2 and 3 hemorrhoids. The overall success rate reported for these procedures in the past ranges from $80 \%$ to $90 \%$ [20-22]. In second grade and third grade hemorrhoids RBL had long term efficacy in terms of lower recurrence and less complications [6, 23-26].

Many comparative studies have been done in past between the two modalities, but none have given a clear advantage of one procedure over another. A meta analysis done by Johanson et al have shown that at the end of twelve months followup period, patients who underwent RBL had low pain and recurrence rate[1].

The advantages of these procedures being the time taken for completing the procedures are short. The patients recover fast after the procedure. Single outpatient sitting is enough for treating multiple hemorrhoids. These kind of outpatient procedures are less painful.

This study was hospital based and done on limited sample. Large community-based studies in future will help throw light on the prevalence of the disease and acceptance of treatment. Randomized controlled trials can be done to provide high quality evidence.

\section{Conclusion}

Based on thisstudies result it can be concluded that both rubber band ligation and injection sclerotherapy are equally effective in the treatment of hemorrhoids. The choice of the procedure should be done based on the patient's willingness and the surgeon's expertise. Early detection and correction can prevent development of complication at later stages.

Contribution by primary investigator: Karpagavel Chandrabose, Guide: Dr. Venkatesh Subbiah

What this study adds on to Existing Knowledge: This study is first of its kind in this region. This study has proven that for grade 2 and 3 hemorrhoidsoutpatients procedures like RBL and IST can be effectively used for management. These procedures have minimal side effects and good compliance. Thereby, reducing the need for hemorroidectomy

\section{Declarations}

Conflict of interest: None declared.

Funding: Nil, Permission from IRB: Yes

Ethical approval: Institutional Ethical Committee, Velammal Medical College, Madurai.

\section{References}

1. Johanson JF, Rimm A. Optimal nonsurgical treatment of hemorrhoids: a comparative analysis of infrared coagulation, rubber band ligation, and injection sclerotherapy. Am J Gastroenterol. 1992 Nov;87(11): 1600-6.

2. Bailey H. Innovations for an Age-Old Problem: Hemorrhoids in the Female Patient. FEMALE PATIENT-PRACTICAL OB GYN MEDICINE THEN OB GYN EDITION. 2004;29(1):17-23.

3. Brown SR. Haemorrhoids: an update on management. Ther Adv Chronic Dis. 2017 Oct; 8 (10): 141-147. doi: 10.1177/2040622317713957. Epub 2017 Jun 21 .

4. Chugh A, Singh R, Agarwal P. Management of hemorrhoids. Indian J Clinic Pract. 2014;25(6):577-80.

5. Johanson JF, Sonnenberg A. The prevalence of hemorrhoids and chronic constipation.An epidemiologic study. Gastroenterology. 1990 Feb;98(2): 380-6.

6. Gartell PC, Sheridan RJ, McGinn FP. Out-patient treatment of haemorrhoids: a randomized clinical trial to compare rubber band ligation with phenol injection. Br J Surg. 1985 Jun;72(6):478-9.

7. Thomson WH. The nature of haemorrhoids. Br J Surg. 1975 Jul;62(7):542-52. 


\section{Original Research Article}

8. Murie JA, Mackenzie I, Sim AJ. Comparison of rubber band ligation and haemorrhoidectomy for second- and third-degree haemorrhoids: a prospective clinical trial. Br J Surg. 1980 Nov; 67(11):786-8.

9. Poen AC, Felt-Bersma RJ, Cuesta MA, et al. A randomized controlled trial of rubber band ligation versus infra-red coagulation in the treatment of internal haemorrhoids. Eur J Gastroenterol Hepatol. 2000 May; 12 (5):535-9.

10. Khan R, Itrat M, Ansari A, Zulkifle M. A study on associated risk factors for haemorrhoids. J Biol Sci Opinion. 2015;3(1):36-8.

11. Johanson JF, Sonnenberg A. Constipation is not a risk factor for hemorrhoids: a case-control study of potential etiological agents. Am J Gastroenterol. 1994 Nov; 89(11):1981-6.

12. Rhee JC, Lee KT. The causes and management of lower GI bleeding: a study based on clinical observations at Hanyang University Hospital. Gastroenterol Jpn. 1991 Jul;26 Suppl 3:101-6.

13. Varma JS, Chung SC, Li AK. Prospective randomised comparison of current coagulation and injection sclerotherapy for the outpatient treatment of haemorrhoids. Int J Colorectal Dis. 1991 Feb;6(1):42-5.

14. Faucheron JL, Gangner Y. Doppler-guided hemorrhoidal artery ligation for the treatment of symptomatic hemorrhoids: early and three-year followup results in 100 consecutive patients. Dis Colon Rectum. 2008 Jun;51(6):945-9. doi: 10.1007/s10350008-9201-z. Epub 2008 Jan 25.

15. Jensen DM, Jutabha R, Machicado GA, et al. Prospective randomized comparative study of bipolar electrocoagulation versus heater probe for treatment of chronically bleeding internal hemorrhoids. Gastrointest Endosc. 1997 Nov;46(5):435-43.

16. Chew SS, Marshall L, Kalish L, et al. Short-term and long-term results of combined sclerotherapy and rubber band ligation of hemorrhoids and mucosal prolapse. Dis Colon Rectum. 2003 Sep;46(9):1232-7.
17. Sagap I, Remzi FH. Controversies in the treatment of common anal problems. World J Gastroenterol. 2006 May 28; 12(20):3146-54.

18. Acheson AG, Scholefield JH. Management of haemorrhoids. BMJ. 2008 Feb 16; 336 (7640):380-3. doi: 10.1136/bmj.39465.674745.80.

19. Bhuiya M, Rahman S, Ali A. Effectivity of injection sclerotherapy on early haemorrhoids reported to surgical outpatient department. JAFMC Bangladesh. 2010; 6(2):25-7.

20. Greca F, Hares MM, Nevah E, et al. A randomized trial to compare rubber band ligation with phenol injection for treatment of haemorrhoids. Br J Surg. 1981 Apr; 68(4):250-2.

21. Sim AJ, Murie JA, Mackenzie I. Three year followup study on the treatment of first and second degree hemorrhoids by sclerosant injection or rubber band ligation. Surg Gynecol Obstet. 1983 Dec;157(6):534-6.

22. Ambrose NS, Morris D, Alexander-Williams J, et al. A randomized trial of photocoagulation or injection sclerotherapy for the treatment of first- and seconddegree hemorrhoids. Dis Colon Rectum. 1985 Apr; 28 (4): 238-40.

23. Sim AJ, Murie JA, Mackenzie I. Comparison of rubber band ligation and sclerosant injection for first and second degree haemorrhoids-- a prospective clinical trial. Acta Chir Scand. 1981;147(8):717-20.

24. Mac Rae HM, McLeod RS. Comparison of hemorrhoidal treatment modalities. A meta-analysis. Dis Colon Rectum. 1995 Jul;38(7):687-94.

25. Iyer VS, Shrier I, Gordon PH. Long-term outcome of rubber band ligation for symptomatic primary and recurrent internal hemorrhoids. Dis Colon Rectum. 2004 Aug;47(8):1364-70.

26. Savioz D, Roche B, Glauser T, et al. Rubber band ligation of hemorrhoids: relapse as a function of time. Int J Colorectal Dis. 1998;13(4):154-6.

\section{How to cite this article?}

Chandrabose K, Subbiah V. Comparison of treatment outcome following rubber band ligation vs injection scleratherapy for treatment of hemorrhoids: a prospective observational study. Surgical Update: Int J surg Orthopedics.2019;5(1):1419.doi:10.17511/ ijoso.2019.101.03. 